\title{
Short-term retention of "surprising" events following different training conditions
}

\author{
RUTH M. COLWILL and ANTHONY DICKINSON \\ The Psychological Laboratory, University of Cambridge, Downing Street, Cambridge CB2 3EB, England
}

\begin{abstract}
Terry and Wagner (1975) have suggested that short-term retention of information about an event is enhanced if the occurrence of the event is surprising. To investigate this idea, we trained two groups of pigeons in a preparatory-releaser procedure in which half the trials started with the presentation of food (the preparatory event). The preparatory food presensation was signaled by an 8-sec white keylight in the signaled, but not in the unsignaled, group. After a retention interval, varying between 2 and $32 \mathrm{sec}$, the releaser stimulus $\left(\mathrm{CS}_{\mathrm{R}}\right)$, a red keylight, was presented for $8 \mathrm{sec}$ in the absence of any reinforcement. The remaining trials were initiated by the presentation of $\mathrm{CS}_{R}$, and the first peck occurring $8 \mathrm{sec}$ after the onset of $\mathrm{CS}_{\mathrm{R}}$ was reinforced by food. The preparatory event controlled responding to $\mathrm{CS}_{\mathrm{R}}$ at the short retention interval, with the level of control declining systematically with increasing retention intervals. On probe test trials, the presentation of the preparatory food event was preceded by a stimulus that had previously been paired $(\mathrm{CS}+)$ or unpaired with food (CS-). Discriminative responding to $\mathrm{CS}_{\mathrm{R}}$ was better following $\mathrm{CS}-$ than following $\mathrm{CS}+$ in the unsignaled, but not the signaled, group. These results suggest that the enhanced retention following surprising preparatory events reflects a generalization decrement induced by changing the signaling conditions between training and testing.
\end{abstract}

The idea that simple associative learning depends upon the extent to which the relevant events, for example, a conditioned (CS) and an unconditioned stimulus (US), are processed during an immediate posttrial period is shared by several learning theories. It is well established that associative learning can be modulated by manipulating the animal's expectancies about the occurrence of the US (see Dickinson \& Mackintosh, 1978; Kamin, 1969), but only recently has this finding been correlated with independent measures of posttrial processing of the US. Terry and Wagner (1975) were able to distinguish different posttrial time courses for the accessibility of information about surprising and expected USs in rabbits using a preparatory-releaser paradigm (Konorski \& Lawicka, 1959). They established an eyeshock as the preparatory stimulus controlling the elicitation of a con-ditioned eyeblink to a releaser stimulus, $\mathrm{CS}_{\mathrm{R}}$. By varying the interval between the preparatory stimulus and the $\mathrm{CS}_{\mathrm{R}}$, Terry and Wagner were able to monitor the time course for which the information about the occurrence of the preparatory stimulus was available for controlling the conditioned response elicited by the $\mathrm{CS}_{\mathrm{R}}$. In addition, an independent

This work was supported by a grant from the Science Research Council. The ONLI computer control system was developed by S. E. G Lea and C. Crook with the help of Grant MRC G970/ 297/B to A. J. Watson. We should like to thank Professor $O$. L. Zangwill for the use of the facilities of the Cambridge Psychological Laboratory. stimulus, CS +, was established as a predictor of eyeshock using a Pavlovian differential conditioning procedure in which a second stimulus, CS-, was not paired with eyeshock. Terry and Wagner were then able to compare retention in a series of probe test trials in which the preparatory stimulus was preceded either by the $\mathrm{CS}+(\mathrm{CS}+/ \mathrm{US}$ episode) or by the $\mathrm{CS}-(\mathrm{CS}-/ \mathrm{US}$ episode). When preceded by $\mathrm{CS}+$, the occurrence of the preparatory eyeshock should have been expected; in contrast, the presentation of CS - would have ensured that the eyeshock was unexpected or surprising. Terry and Wagner reported better delayed discriminative performance to $\mathrm{CS}_{\mathrm{R}}$ following CS - / US episodes than following $\mathrm{CS}+/$ US episodes, a finding they interpreted as evidence that surprising events receive more sustained processing or "rehearsal" during a postpresentation period.

Terry and Wagner also entertained an account of somewhat less theoretical interest. They pointed out that superior retention for a "surprising" eyeshock would be expected if a CS - /US episode was reacted to as more similar to the preparatory eyeshock presentations given during initial training than was a CS + /US episode. Under these circumstances, the inferior performance following a CS + /US episode might simply reflect a generalization decrement. A potential reason for such a decrement is revealed by a comparison of the signaling conditions during preparatory-releaser training and testing. During both testing with CS-/US episodes and training, 
the occurrence of the preparatory eyeshock was unsignaled, whereas during a CS + /US test trial its occurrence was signaled by $\mathrm{CS}+$. If the way in which an animal encodes information about the occurrence of a preparatory event depends upon whether or not it is signaled, a change in the signaling conditions between training and testing should induce a generalization decrement. The obvious implication is that the superior retention of $\mathrm{CS}-/ \mathrm{US}$ episodes should be attenuated by signaling the preparatory stimulus during initial preparatory-releaser training.

An advantage of the generalization decrement account is that it provides a potential explanation for why Bottjer and Hearst's (1979) application of Terry and Wagner's preparatory-releaser procedure with pigeons failed to show a significant difference in retention following $\mathrm{CS}-/ \mathrm{US}$ and $\mathrm{CS}+/ \mathrm{US}$ episodes. In this study, the presentation of food acted as a preparatory signal for whether or not an ensuing $\mathrm{CS}_{\mathrm{R}}$ would be reinforced with food. A distinguishing feature of Bottjer and Hearst's procedure was that the presentation of the preparatory food was accompanied by an auditory stimulus which might have been established as a potential signal even though it was only partially reinforced. The consistent presentation of the auditory stimulus on probe test trials ensured that the signaling conditions were basically similar to those employed during training and thus minimized any generalization decrement.

The aim of the present experiment was to evaluate the generalization decrement account using a preparatory-releaser procedure with pigeons. Initially, two groups of pigeons experienced pairings of a stimulus, CS + , with food presentations to establish it as a predictor of food; intermixed with these pairings were nonreinforced presentations of a control stimulus, $\mathrm{CS}-$. Training on the preparatoryreleaser procedure followed. Because Bottjer and Hearst found systematic and stable retention gradients only if a feature-negative training procedure was used, we employed a similar schedule. In this schedule, the birds received an intermixed series of two types of trials: $P$ trials, in which the $C_{R}$ was preceded by the presentation of a preparatory food presentation, and $\overline{\mathrm{P}}$ trials, in which the $\mathrm{CS}_{\mathrm{R}}$ alone was presented. The sequence of events experienced on each type of trial is illustrated in Figure 1. For both groups, $\overline{\mathrm{P}}$ trials simply consisted of reinforced presentations of $C S_{R}$. For the unsignaled group, $P$ trials started with a preparatory food presentation, followed, after a variable retention interval, by the nonreinforced presentation of $\mathrm{CS}_{\mathrm{R}}$. The signaled group experienced the same sequence of events on $P$ trials, except that the preparatory food was always preceded by a signal that differed from $\mathrm{CS}+, \mathrm{CS}-$, and $\mathrm{CS}_{\mathrm{R}}$. With this schedule, we expected that the preparatory food presentation would come to control

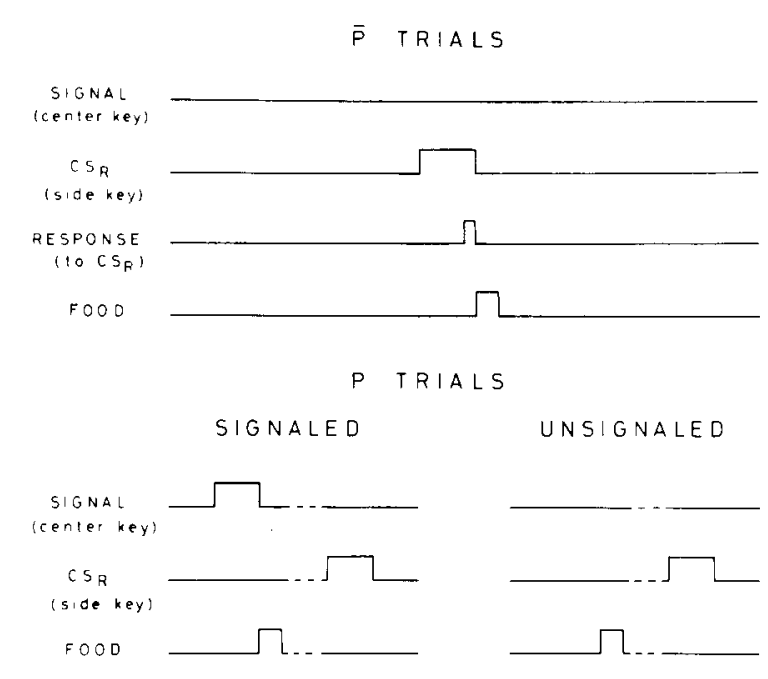

Figure 1. Diagram of the events constituting $P$ and $\bar{P}$ trials for the signaled and unsignaled groups during preparatory-releaser training.

responding at short retention intervals so that the birds would respond less to $\mathrm{CS}_{\mathrm{R}}$ on $\mathbf{P}$ trials than on $\bar{P}$ trials. Furthermore, the time course for retention of information about the occurrence of the preparatory food could be determined by comparing responding to $C S_{R}$ on $\mathbf{P}$ trials with that on $\bar{P}$ trials after the various retention intervals.

Following preparatory-releaser training, discriminative performance was tested on probe test trials initiated by either a CS + /US or a CS - /US episode. The generalization decrement explanation predicts that enhanced retention following a CS-/US episode should only be observed in the unsignaled condition. In contrast, there are no obvious reasons why the signaling conditions during training should affect test performance if retention is a direct function of the "surprisingness" of the preparatory stimulus per se. Probe test trials that were initiated by either $\mathrm{CS}+$ alone (CS $+\overline{\mathrm{US}}$ episodes) or $\mathrm{CS}$ alone (CS $-/ \overline{\mathrm{US}}$ episodes) were also given.

\section{METHOD}

\section{Subjects}

The subjects were 12 adult pigeons, maintained at $80 \%$ of their free-feeding weights by food deprivation. They were housed in individual cages with water freely available. Before the start of the experiment, the subjects were divided into two groups, one signaled and the other unsignaled $(N=6)$. Four of the birds in each group were experimentally naive, but the remaining subjects had been used in a pilot study for the present experiment and had had previous experience of preparatory-releaser training.

\footnotetext{
Apparatus

Training and testing were conducted in two Campden Instruments pigeon chambers, enclosed in dark, sound-attenuating chests. A standard Campden Instruments intelligence panel, with an additional key inserted midway between and level with the two side keys, constituted one wall of each chamber. The side keys could be transilluminated with red light and the center key could
} 
display a plain white field or a single horizontal or vertical white line on a dark background. An aperture which gave access to the food magazine was situated below the center key. This aperture was illuminated with white light whenever food was presented. Both chambers were interfaced with a Modular One computer (Computer Technology Ltd.), which controlled the stimulus events and monitored responses.

\section{Procedure}

In the first session, the pigeons were allowed to eat freely from the food magazine for $30 \mathrm{~min}$. In the second and third sessions, the food magazine was presented for 8 and $4 \mathrm{sec}$, respectively, 60 times on a variable-time 30 -sec schedule.

Discrimination training. All subjects received seven daily sessions, each containing 80 trials. Each trial commenced with the presentation of one of two stimuli, the CS + or the CS - on the center key for $8 \mathrm{sec}$. The presentation of $\mathrm{CS}+$ terminated with the presentation of food for $4 \mathrm{sec}$, whereas CS - presentations were followed by a 4-sec no-food period. Each session consisted of $40 \mathrm{CS}+$ trials and $40 \mathrm{CS}$ - trials, presented in a semirandom order with a 20 -sec intertrial interval (ITI). For half the subjects in each group, $\mathrm{CS}+$ was the horizontal line and CS - was the vertical line; these contingencies were reversed for the remaining subjects.

Preparatory-releaser training. The naive subjects received 20 daily sessions, each consisting of 36 preparatory-releaser trials, separated by an ITI of $60 \mathrm{sec}$. On half the trials, P trials, a 4-sec food presentation served as the preparatory stimulus and always terminated with the illumination of one of the side keys with red light, which served as the releaser stimulus, $\mathrm{CS}_{\mathrm{R}}$ (see Figure 1). After $8 \mathrm{sec}$, the key darkened automatically. Initially, the retention interval between the end of the preparatory stimulus and the onset of the $C_{R}$ was 0 sec. Intervals of $2,8,16$, and $32 \mathrm{sec}$ were then gradually introduced on some trials. The number of trials with each retention interval on each training session is given in Table 1. For the unsignaled group, a $\mathbf{P}$ trial was initiated by the preparatory stimulus itself, whereas for the signaled group, the $\mathrm{P}$ trial started with the presentation of a plain white field on the center key for $8 \mathrm{sec}$, which was then followed immediately by the preparatory food stimulus (see Figure 1). On the 18 remaining trials, $\overline{\mathrm{P}}$ trials, no preparatory stimulus occurred and, for both groups, the start of a trial was marked by the presentation of $\mathrm{CS}_{\mathrm{R}}$ on one of the side keys. A fixed-interval 8 -sec schedule was programmed on the illuminated side key. Thus, the first peck after $8 \mathrm{sec}$ darkened the key and initiated a 4 -sec food presentation. The $\mathrm{CS}_{\mathrm{R}}$ occurred with equal frequency on the right and left side keys on $P$ and $\bar{P}$ trials at each retention interval. Trials were presented in a semirandom order. Ten reinforced CS + and 10 nonreinforced CS - discrimination trials, separated by an ITI of $60 \mathrm{sec}$, were included at the start of each preparatory-releaser training session in order to maintain the previously acquired discrimination.

Following magazine and discrimination training, the four experimentally sophisticated birds received 38 sessions of training with a preparatory-releaser procedure that was similar to that used in the unsignaled condition and then preliminary testing for retention following $\mathrm{CS}+/ \mathrm{US}$ and $\mathrm{CS}-/ \mathrm{US}$ episodes. After this

Table 1

Number of Trials per Session at Each Retention Interval

\begin{tabular}{crrrrr}
\hline & \multicolumn{5}{c}{ Retention Interval (in Seconds) } \\
\cline { 2 - 6 } Sessions & 0 & 2 & 8 & 16 & 32 \\
\hline $1-6$ & 18 & & & & \\
$7-8$ & 6 & 12 & & & \\
$9-10$ & 6 & 6 & 6 & & \\
$11-14$ & & 6 & 6 & 6 & \\
$15-20$ & & 6 & & 6 & 6 \\
\hline
\end{tabular}

initial testing, the subjects were divided into a signaled group and an unsignaled group, counterbalanced with respect to the type of stimulus used as $\mathrm{CS}+$. They were then given 18 daily sessions of preparatory-releaser training identical to the terminal sessions for the naive birds, with the full range of retention intervals.

Test sessions. The testing procedure was identical for all subjects irrespective of their experimental history. This phase consisted of six test sessions which were alternated with five retraining sessions. The retraining sessions were identical to the final sessions of preparatory-releaser training. To maintain the signaling value of the stimuli, each test session started with 10 reinforced $\mathrm{CS}+$ and 10 nonreinforced $\mathrm{CS}-$ presentations. There then followed six $P$ and six $\bar{P}$ trials identical to those given in the terminal sessions of the preparatory-releaser training. The test session ended with a block of 24 trials. This block contained eight test trials and four baseline trials presented in a semirandom order. Two of the baseline trials were $\mathbf{P}$ trials and the other two were $\overline{\mathrm{P}}$ trials. In an attempt to equate any proactive influence from prior trials, each test and baseline trial within a test session was preceded by a preparatory-releaser trial with a 2 -sec retention interval. This preparatory-releaser trial was always a $\mathbf{P}$ trial during the first three test sessions and a $\overline{\mathbf{P}}$ trial during the second triad of test sessions. The retention interval was the same on all the eight test trials and four baseline trials within a test session but varied across the six test sessions as follows: 32,16 , $2,2,16$, and $32 \mathrm{sec}$.

A test trial began with the illumination of the center key, with $\mathrm{CS}+$ on four of the eight test trials within a session. The remaining test trials were initiated by the presentation of $\mathrm{CS}-$. After $8 \mathrm{sec}$, the keylight was turned off and the preparatory food stimulus was presented on half the trials on which each stimulus occurred; on the remaining trials, a 4-sec no-food period followed. Thus, there were four different types of test trials: $\mathrm{CS}+/ \mathrm{US}$ and $\mathrm{CS}-/ \mathrm{US}$ trials in which the presentation of the preparatory food was preceded by either $\mathrm{CS}+$ or $\mathrm{CS}-$, respectively, and $\mathrm{CS}+\overline{\mathrm{US}}$ and $\mathrm{CS}-\overline{\mathrm{USS}}$ trials in which the presentation of a no-food period was preceded by $\mathrm{CS}+$ and $\mathrm{CS}-$, respectively. These episodes were immediately followed by a retention interval, after which the $C_{R}$ was presented. The ensuing food reinforcer was delivered in accordance with the contingencies operating during preparatory-releaser training. The $\mathrm{CS}_{\mathrm{R}}$ occurred once on the left side key and once on the right side key for the two presentations of each type of test trial within a session.

\section{RESULTS}

Performance during preparatory-releaser training was measured by the number of keypecks to $\mathrm{CS}_{\mathrm{R}}$ during the first $8 \mathrm{sec}$ of this stimulus on $P$ and $\overline{\mathbf{P}}$ trials. Discrimination ratios were calculated as the proportion of responses on $\overline{\mathbf{P}}$ trials relative to the total number of responses on both $P$ and $\bar{P}$ trials $[\overline{\mathrm{P}} /(\mathrm{P}+\overline{\mathrm{P}})]$ for each retention interval during the last two sessions of preparatory-releaser training. Ratios greater than .5 indicate that the preparatory food episode exerted control over responding. Discrimination ratios for each group are presented in Figure 2.

With increasing retention intervals, the discrimination ratios decreased systematically $[F(2,20)=$ $41.47, \mathrm{p}<.01$ ], indicating a progressive loss of discriminative control by the preparatory food stimulus. There was no difference between the ratios of the two groups $(\mathrm{F}<1)$, nor was the Group by Retention 


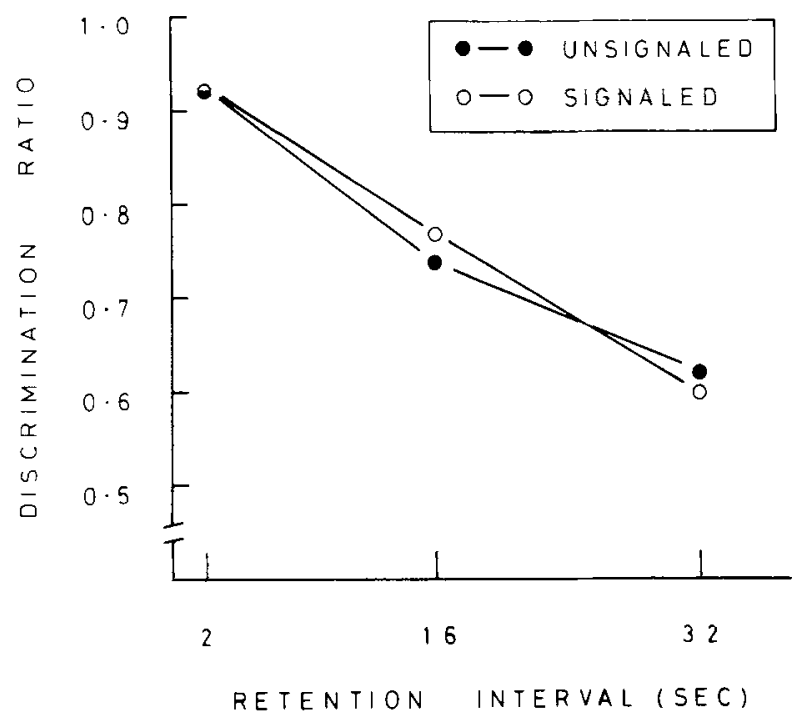

Figure 2. Discrimination ratios for the signaled (SIG) and unsignaled (UNSIG) groups during the last two sessions of preparatory-releaser training plotted as a function of retention interval for the two groups $(N=6)$.

Interval interaction significant $(\mathrm{F}<1)$. On $\overline{\mathbf{P}}$ trials, the mean number of responses per $\mathrm{CS}_{\mathrm{R}}$ presentations during the last two sessions was 11.6 for the unsignaled group and $\mathbf{1 6 . 3}$ for the signaled group, which did not differ significantly $[\mathrm{t}(10)=1.93$, $\mathrm{p}>.05]$.

Because all the test trials were initiated by either $\mathrm{CS}+$ or $\mathrm{CS}-$, a discrimination ratio measure would have confounded the effect of these signals on responding on $\mathbf{P}$ trials with their effect on $\overline{\mathbf{P}}$ trials. Consequently, performance on test trials was measured in terms of the number of responses to $\mathrm{CS}_{R}$ per trial, separately for $P$ and $\bar{P}$ test trials. Figure 3 illustrates the responses per trial at each retention interval averaged over all test trials initiated by the preparatory food presentation, $P$ trials (top panel), and a no-food period, $\overline{\mathrm{P}}$ trials (bottom panel). Using this measure, good discriminative performance is indicated by a low level of responding on $P$ trials. Figure 3 shows that discriminative performance decreases systematically with increasing retention intervals in both groups $[\mathrm{F}(2,20)=12.13, \mathrm{p}<.01]$.

The results of prime interest are the relative performances of the two groups on $\mathbf{P}$ test trials initiated by $C S-/ U S$ and $C S+/ U S$ episodes. The important finding was that the unsignaled group showed less responding and, therefore, better retention following CS - /US episodes than following CS + /US episodes, whereas the opposite pattern was observed in the signaled group. This conclusion was supported by a marginally significant interaction between the type of initiating episode and group $[\mathrm{F}(1,10)=4.37, \mathrm{p}=$ .06] on $\mathrm{P}$ trials. However, the absence of a significant Group by Initiating Episode by Retention
Interval interaction $[F<1]$ does not support the suggestion in the graphic data (see Figure 3 top panel) that the difference between responding on $\mathrm{CS}-/ \mathrm{US}$ and $\mathrm{CS}+/ \mathrm{US}$ in the two groups interacted with the length of the retention interval. To determine the source of the Group by Initiating Episode interaction, separate analyses on performance on $P$ trials were performed for each group. There was a significant difference between responding on CS-/US and $\mathrm{CS}+/$ US trials in the unsignaled group $[\mathrm{F}(1,10)=$ $8.34, \mathrm{p}<.02]$ but not in the signaled group $[\mathrm{F}(1,10)$ $=1.19, \mathrm{p}>.25]$.

Performance on $\overline{\mathbf{P}}$ trials (see Figure 3, bottom panel) was not significantly affected by the retention interval. Neither the main effect of retention interval

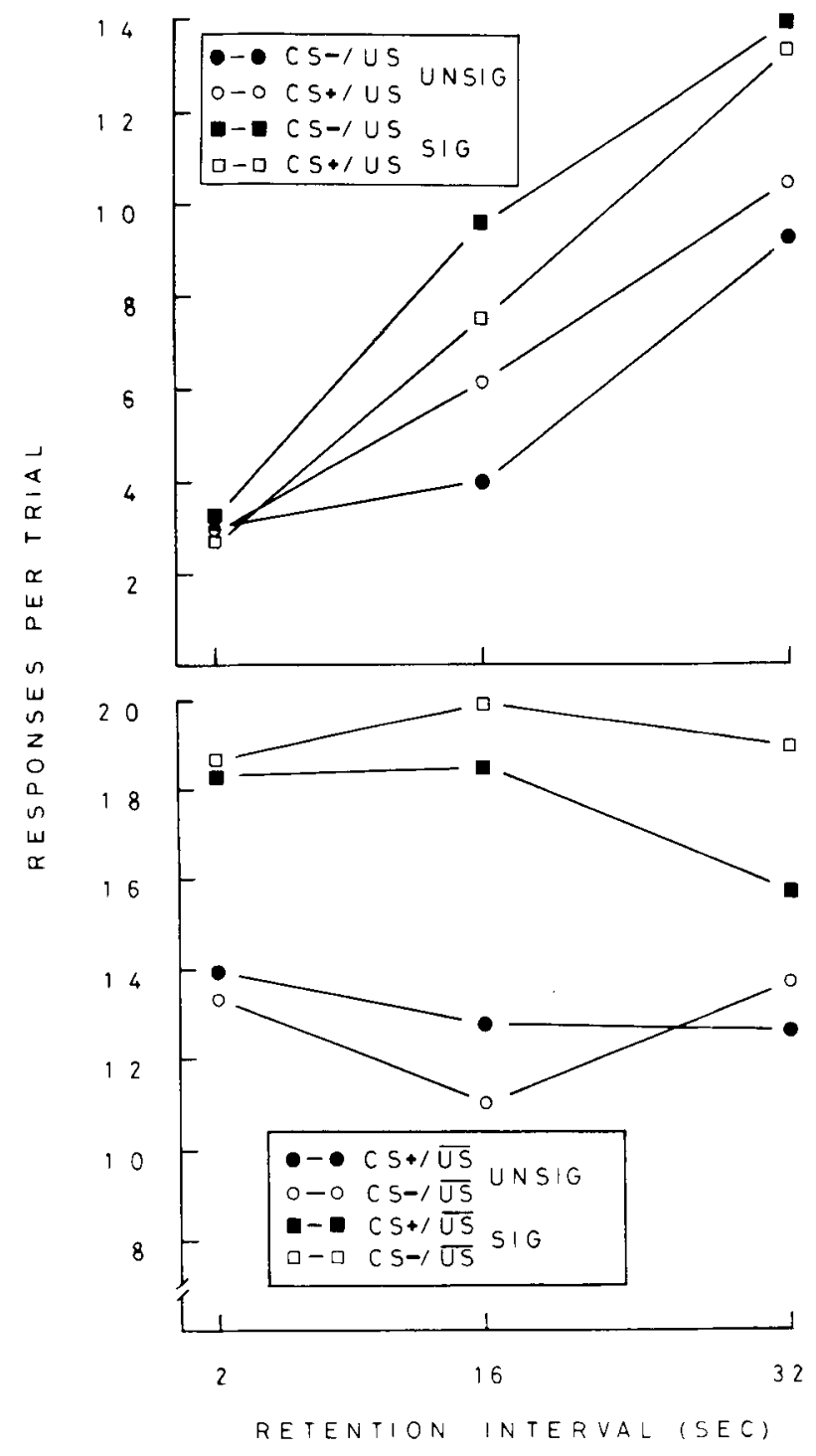

Figure 3. Mean performance of the signaled (SIG) and unsignaled (UNSIG) groups at each test retention interval on test trials. Top panel: trials initiated by the preparatory food stimulus (P trials). Bottom panel: trials initiated by a no-food period $\overline{\mathbf{P}}$ trials). 
nor interactions involving this factor were significant $[F(2,20)<1.37, p>.10]$. Although the interaction between the groups and the type of initiating episode was also marginally significant $[\mathrm{F}(1,10)=3.62$, $.05<\mathrm{p}<.10$ ], separate analyses of performance within each group revealed neither a significant effect of trial type $[F(1,10)<2.28, p>.10$ in both cases] nor a significant interaction between this factor and retention interval $[F<1$ in both cases].

The CS + was effectively maintained as a signal for food in both groups during testing. The mean number of responses to $\mathrm{CS}+$ and $\mathrm{CS}-$ per test session was 118.2 and 40.4 , respectively, for the signaled group and 81.9 and 18.4 , respectively, for the unsignaled group. There was a significant difference between the levels of responding to $\mathrm{CS}+$ and $\mathrm{CS}-[\mathrm{F}(1,10)=22.33, \mathrm{p}<.01]$, but the level of responding in the two groups did not differ $[F(1,10)$ $=2.33, \mathrm{p}>.10]$.

\section{DISCUSSION}

The pattern of discriminative performance on test trials in the unsignaled group replicated Terry and Wagner's (1975) finding of superior retention following $\mathrm{CS}-/ \mathrm{US}$ episodes relative to $\mathrm{CS}+/ \mathrm{US}$ episodes. A comparable effect, however, was not observed in the signaled group; if anything, a CS - /US episode tended to produce poorer discriminative performance in this group. These findings have two main implications. First, they suggest that the difference in discriminative performance following CS-/US and CS +/US episodes in the unsignaled group did not arise from unconditioned effects of these episodes on subsequent responding to $\mathrm{CS}_{\mathrm{R}}$. If this were so, we should have observed an equivalent difference in the signaled group. Secondly, the fact that the influence of the initiating episode can be manipulated by varying the signaling conditions during preparatory-releaser training is not readily accommodated by the idea that $\mathrm{CS}-/ \mathrm{US}$ episodes produce more sustained processing or "rehearsal" of information about the occurrence of the US (Wagner, 1978; Whitlow, 1976). Rather, the results suggest that the encoding of information about the preparatory US is affected by the signaling conditions present during training, so that a change in signaling conditions between training and testing induces a generalization decrement in the discriminative control exerted by the preparatory stimulus.

There are a number of reasons why such a variation in encoding may have occurred. For instance, the presence of a signal during training may have allowed the birds to anticipate the presentation of the preparatory food and thus ingest a quantity that differed from the intake on unsignaled presentations. If the discriminative control exerted by the prepara- tory food episode was sensitive to the magnitude of food ingested, the pigeon would suffer a generalization decrement when the signaling conditions were shifted between training and testing. An alternative explanation, considered by Terry and Wagner (1975), focuses on the role of the response pattern generated by exposure to episodes involving signaled US presentations. In the case of the pigeon, it is well known that signaling food presentations by the illumination of a keylight results in the bird's approaching and contacting the key during its illumination (Hearst \& Jenkins, 1974). In the unsignaled condition, discriminative control by the preparatory food would have been established in the absence of such responses so that their elicitation on test trials initiated by a $\mathrm{CS}+/ \mathrm{US}$ episode may have induced a generalization decrement. Such an effect would not have operated in the signaled group for which discriminative control was established in the presence of these responses.

Finally, it should be noted that the generalization decrement account can probably be extended to other demonstrations of enhanced retention of information about surprising events. Maki (1979) has recently observed superior retention following a CS-/US episode when short-term memory was probed by a delayed conditional simultaneous discrimination. In this experiment, pigeons were required to choose one of two simultaneously presented colored keys on the basis of whether or not their illumination had been preceded by the delivery of food. The presentation of a CS-/US episode on test trials maintained better discriminative performance after a delay than did a CS + /US episode. We have been able to replicate this effect when the presentation of the preparatory food was unsignaled during initial baseline training (Colwill \& Dickinson, 1980). Furthermore, the effect could be abolished, as in the present experiment, and even reversed by giving initial training with signaled preparatory food presentations. The clear implication is that, in assessing the theoretical significance of performance on probe test trials in short-term memory procedures, the relationship between the signaling conditions operative during training and testing must be taken into account.

Terry and Wagner (1975) reported that on $\bar{P}$ trials the presentation of an initial CS + /US episode tended to produce discriminative performance that was similar to that seen following the preparatory stimulus itself. They suggested that $\mathrm{CS}+$, a predictor of the preparatory stimulus, can act as an effective substitute for this stimulus. Although we have been able to replicate this finding with pigeons by using a delayed conditional discrimination (Colwill \& Dickinson, 1980), the present experiment did not show a comparable effect with a preparatory- 
show a comparable effect with a preparatoryreleaser procedure. Bottjer and Hearst (1979) also failed to find that $\mathrm{CS}+$ acted like the preparatory stimulus in their feature-negative condition, although such a substitution did occur in the featurepositive group. In contrast with these findings, Maki (1979) reported that the presentation of a $\mathrm{CS}+\overline{\mathrm{US}}$ episode enhanced discriminative performance that was appropriate for $\overline{\mathbf{P}}$ trials. In view of the variety of training procedures used in these different studies, it is premature to speculate on the mechanisms underlying these divergent findings for $\overline{\mathbf{P}}$ test trials.

\section{REFERENCES}

Bottjer, S. W., \& Hearst, E. Food delivery as a conditional stimulus: Feature-learning and memory in pigeons. Journal of the Experimental Analysis of Behavior, 1979, 31, 189-207.

Colwill, R. M., \& Dickinson, A. Short-term retention of "surprising" events by pigeons. Quarterly Journal of Experimental Psychology, 1980, 32, 539-556.

Dickinson, A., \& Mackintosh, N. J. Classical conditioning in animals. Annual Review of Psychology, 1978, 29, 587-612.

Hearst, E., \& Jenkins, H. M. Sign tracking: The stimulus- reinforcer relation and directed action. Austin, Tex: Psychonomic Society, 1974.

Kamin, L. J. Predictability, surprise, attention and conditioning. In B. Campbell \& R. M. Church (Eds.), Punishment and aversive behavior. New York: Appleton-Century-Crofts, 1969.

Konorsk 1, J., \& Lawicka, W. Physiological mechanism of delayed reactions: 1 . The analysis and classification of delayed reactions. Acta Biologia Experimentalis, 1959, 19, 175-197.

MAKI, W. S. Pigeons' short-term memories for surprising vs. expected reinforcement. Animal Learning \& Behavior, 1979, 7, 31-37.

TERry, W. S., \& Wagner, A. R. Short-term memory for "surprising" vs. "expected" USs in Pavlovian conditioning. Journal of Experimental Psychology: Animal Behavior Processes, 1975, 1, 122-133.

WAgner, A. R. Expectancies and the priming of STM. In S. H. Hulse, H. Fowler, \& W. K. Honig (Eds.), Cognitive processes in animal behavior. Hillsdale, N.J: Erlbaum, 1978.

Whitlow, J. W. The dynamics of episodic processing in Pavlovian conditioning. In D. L. Medin, W. A. Roberts, \& R. T. Davis (Eds.), Processes of animal memory. Hillsdale, N. J.: Erlbaum, 1976.

(Received for publication March 14, 1980; revision accepted June 24,1980 .) 